\title{
A GEOGRAFIA FÍSICA NO BRASIL: UM PANORAMA QUANTITATIVO A PARTIR DE PERIÓDICOS NACIONAIS (1928-2006) ${ }^{1}$
}

Antônio Carlos Vitte

Programa de Pós-Graduação em Geografia, Unicamp, Campinas (SP), Brasil. Pesquisador CNPq vitte@uol.com.br.

\begin{abstract}
Resumo
A geografia física é um campo (cf. Bourdieu, 1992) temático que procura problematizar a natureza e sua relação com a sociedade pelo viés da Ciência Geográfica. O objetivo deste trabalho foi o de realizar um estudo sobre a produção da geografia física no Brasil a partir de artigos publicados em periódicos nacionais, correlacionando esta produção às transformações internas da ciência geográfica (Gregory, 1992). Foram realizados levantamentos em 22 periódicos nacionais, em um período temporal de 78 anos (1928-2006). Em termos absolutos foram produzidos 6.189 artigos, sendo que destes, $2.298(37,1 \%)$ artigos tinham como temática a geografia física e 3.891(62,9\%) abordavam a geografia humana. A média geral de artigos para o período foi de 221,0 artigos/ano, sendo que a média de artigos de geografia física foi de 82,1 artigos/ano, enquanto que 138,9 foi a média de produção de artigos que não tratavam de geografia física. Enquanto na década de 1920 os artigos de geografia física correspondiam à $0,1 \%$ do total de artigos, nas décadas de 1940, 1950, 1960 e 1970; este percentual alcançou 19,1\%, 19,8\%, $20,6 \%$ e $15,7 \%$ respectivamente. Quanto à produção de geografia humana, foram publicados 3180 artigos, que percentualmente representa $51,3 \%$ dos artigos produzidos no período de 1928 à 2006. A análise dos dados demonstrou que o aumento na produção da geografia física está relacionado tanto a processos que envolvem a especialização de seus subcampos e a incorporação de novas tecnologias, que permitiram a institucionalização do saber geográfico a serviço do Estado planejador e interventor do período Keynesiano.
\end{abstract}

\section{Resumen}

La geografía física es una área (cf. Bourdieu, 1992) temática que pretende estudiar la naturaleza y su relación con la sociedad en una visión de la Ciencia Geográfica. El objetivo de este trabajo fue de realizar un estudio sobre la producción de la geografía física en el Brasil a partir de artículos publicados en periódicos nacionales, correlacionando esta producción a las transformaciones internas de la ciencia geográfica (Gregory, 1992). Las informaciones fueron retiradas de 22 periódicos nacionales, en un periodo temporal de 78 años (1928-2006). En dados absolutos fueron producidos 6,189 artículos, siendo que, $2,298(37.1 \%)$ artículos tenían como tema la geografía física y $3,891(62,9 \%)$ abarcaban la geografía humana. La media general de los artículos para el periodo fue de 221.0 artículos/año, siendo que la media de artículos de geografía física fue de 82.1 artículos/año, en cuanto que 138.9 fue la media de producción de artículos que no trataban de geografía física. En cuanto que en la década de 1920, los artículos de geografía física correspondían a $0.1 \%$ del total de artículos, en las décadas de 1940 , 1950,1960 y 1970 ; este porcentaje alcanzó $19.1 \%$, $19.8 \%, 20.6 \%$ y $15.7 \%$ respectivamente. El análisis de las informaciones demostró que el aumento en la producción de geografía física está relacionada tanto a los procesos que abordan la especialización de sus sub-áreas y a la incorporación de nuevas tecnologías, que permitieron la institucionalización del saber geográfico al servicio del Estado planeador e interventor de la revista Keynesiano.

Palavras-chave: Geografia Física. Epistemologia. Brasil.

Palabras-clave: Geografía Fisica. Epistemología. Brasil.

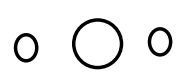

\section{INTRODUÇÃO}

A geografia física é um campo (BORDIEU, 1992) temático que procura problematizar a natureza e sua relação com a sociedade pelo viés da Ciência Geográfica. O objetivo deste trabalho foi o de realizar o estudo sobre a produção da geografia física no Brasil, de 1928 à 2006, a partir de artigos publicados em periódicos nacionais de Geografia.

Para Gregory (1992) a geografia física caracteriza-se por apresentar mudanças em seu campo temático e metodológico provocadas principalmente por transformações internas aos seus postulados, em que, devido 
ao pragmatismo e ao uso constante e cada vez maior de técnicas analíticas promovem mudanças em seus referencias analíticos. No entanto, apesar de reconhecermos a importância da abordagem internalista na Ciência, não podemos de considerar que a mesma é o produto de transformações sociais e culturais que acontecem ao longo do tempo histórico e aos poucos reconstrói as visões de mundo (KHUN, 1992). Ou seja, não podemos deixar de considerar que existe também uma sociologia da ciência e uma política das corporações que promovem discussões e embates, mais ou menos intensos, a depender do poder político das corporações, mas que imprimem uma marca importante nas mudanças de perspectiva das pesquisas e na redefinição de seus objetos particulares frente as exigências sociais e políticas.

Neste trabalho explicitamente não trataremos das relações entre o internalismo e o externalismo no processo de desenvolvimento e consolidação da geografia física no Brasil, apenas faremos uma análise fundamentada em dados quantitativos que foram levantados em 22 periódicos de Geografia e que se constituíram ou se constituem ainda, referências importantes para o fazer geografia no Brasil.

\section{Interpretações sobre a História da Geografia Física no Brasil}

Camargo (1998) realizou uma reflexão teórica e metodológica sobre a biogeografia no Brasil, preocupando-se com seu objeto de estudo, campo e métodos de análise, bem como procurando verificar quais as relações com a Geografia Física e com a Geografia de modo geral. O principal objetivo foi o de levantar, analisar e refletir sobre a evolução, a produção e as tendências futuras da biogeografia, no âmbito da Geografia, através da análise de trabalhos oriundos das mais variadas fontes e dos mais variados autores, sendo, contudo, diretamente relacionados com a temática biogeográfica.

$\mathrm{O}$ autor discutiu questões relevantes sobre as naturezas do pensamento biogeográfico brasileiro, do ponto de vista do geógrafo, assim como verificou como os geógrafos nacionais têm encarado esse ramo do saber. Sobre a evolução do pensamento biogeográfico, no âmbito da ciência geográfica, o autor apresenta amplo relato histórico desde o período do descobrimento do Brasil (1500) até a última década do século XX. Sobre a análise dos trabalhos biogeográficos no âmbito das revistas geográficas e outras publicações levantadas o autor apresenta dados relevantes que demonstram os inúmeros enfoques resultantes da ciência complexa que é a biogeografia.

Viadana (2004) relata que entre os geógrafos físicos, os biogeógrafos foram os primeiros a perceber a dinâmica integrada dos componentes paisagísticos, como a estrutura geológica, clima, solo, relevo, vegetação e hidrografia, sem incidir para a avaliação isolada e individualizante do espaço geográfico. Assim, os biogeógrafos deram início a novas tendências no seu campo específico de estudo, fundamentados numa visão holística ou de conjunto, proporcionando grande progresso na produção biogeográfica e na própria Geografia.

Suertegaray \& Nunes (2001) discutem a natureza e a produção da Geografia Física atual no âmbito da ciência geográfica, a partir do levantamento feito nos Anais do XII Encontro Nacional de Geógrafos, realizado em Florianópolis (SC) em julho de 2000 e do 8 Encontro de Geógrafos da América Latina, realizado em Santiago (Chile), em março de 2001. Os autores relatam que a intenção foi pensar sobre a produção geográfica referente ao conhecimento que se denominou Geografia Física, ou seja, o conhecimento referente à natureza.

Cidade (2001) realizou um amplo levantamento bibliográfico e histórico com o objetivo de "explorar formas de abordagem da relação sociedade-natureza em diferentes fases da longa constituição dos fundamentos do pensamento geográfico'(p.101). Ainda, segundo Cidade (2001, p.116), "no longo percurso em busca de uma identidade aglutinadora e do estabelecimento de bases epistemológicas convincentes, a 
geografia tem sido objeto de inúmeras críticas". Enquanto parte dessas críticas provém de áreas externas à disciplina, a maior fonte de cobranças tem sido interna. A expressão das dificuldades encontradas pela geografia, às quais se atribui a impossibilidade de constituir-se como síntese, está em uma espécie de dualidade que, de resto, não atinge apenas essa disciplina. Essa dualidade expressa-se particularmente no tratamento das relações sociedade-natureza.

Com relação à separação entre sociedade e natureza, freqüentemente considerada característica essencial do capitalismo, com reflexos nos sistemas de pensamento que acompanharam Cidade (2001) relata que mostrou-se mais antiga, aparecendo desde os povos primitivos e que o desenvolvimento social e econômico acompanhou-se de uma transformação progressiva da natureza. "Em síntese, torna-se cada vez mais claro que, enquanto a separação entre sociedade e natureza é bastante antiga, o capitalismo, juntamente com os sistemas de conhecimento associados à sua emergência, tornou-se mais aguda essa separação, estabelecendo tendências a uma ruptura"(p. 117).

Monteiro (2002, p.4) traçou o panorama da Geografia que se faz no Brasil, usando como estratégia as seguintes normas:

a) Assentar as bases da avaliação através dos vetores básicos da produção geogeráfica, a saber: a Universidade como centro de produção; a Fundação IBGE como aplicação oficial e a Associação dos Geógrafos Brasileiros como refletor das tendências e conflitos na comunidade de geógrafos do Brasil;

b) Observar, ao longo do século, os eventos básicos no desenvolvimento cronológico linear, de modo a possibilitar uma articulação sincrônica capaz de sugerir definição de momentos ou fases característicos nesta evolução;

c) Integrar essa possível periodização em face de uma projeção intrageográfica na produção brasileira, com a consideração dos insumos advindos dos eventos mundiais e as respectivas repercussões na Geografia nos centros hegemônicos de saber, do poder econômico e político mundial. Em suma, avaliar as mutações no mundo e em suas geografias ao longo do tempo em que se avaliam as ligações emanadas dos centros polarizadores e recebidas nas grandes periferias nesta perspectiva global caracterizada, sobretudo, por grandes diferenças nos graus de desenvolvimento.

d) Finalmente, procurar, nesta periodização, articular as relações entre as direções e tendências da Geografia, com os projetos políticos vigentes no país ao longo do século.

O panorama elaborado por Monteiro (2002) foi dividido em duas partes. Na primeira foram descritas as grandes etapas evolutivas; início do século XX (1900-1935), chamada de preparação para a Geografia Científica; alvorecer da Geografia Científica (1935-1968). Na segunda parte foi descrita a travessia da grande crise histórica: soleira do pós-moderno e as grandes mutações (1968-1973); entrada no pós-moderno (1973-1984); e final do século XX e as múltiplas incertezas no início do século XXI (1984-2001).

Conti (1996) relata que o papel dos geógrafos brasileiros tem sido mais destacado na realização de trabalhos climatológicos na América do Sul, principalmente devido, em grande parte, à criação dos cursos de Geografia em nível superior, no quadro das antigas Faculdades de Filosofia, Ciências e Letras, surgidas, pioneriamente, em São Paulo, em 1934, e no Rio de Janeiro em 1935. Relata que o modelo de formação geográfica que foi caracterizada pela grande abrangência e ampla integração imprimiu uma diretriz especial aos estudos climatológicos, que passaram a ser feitos dentro de uma perspectiva espacial, constituindo parte integrante dos estudos regionais como uma característica antropocêntrica, por ser uma ciência que estuda, ao mesmo tempo, a natureza e a sociedade.

Sant'Anna Neto (2001) propõe uma Geografia do clima, contrapondo-se à noção de uma climatologia geográfica. Para tanto, recorrendo aos primórdios da climatologia no Brasil, buscou estabelecer as bases 
conceituais da incorporação do fenômeno climático `a ciência geográfica. Discutiu a revolução paradigmática iniciada por Sorre (1951) e a proposta por Monteiro (1991), a partir da incorporação da noção de ritmo como novo paradigma para a análise geográfica do clima e relata a necessidade de se produzir uma readequação destes conceitos à luz do processo de globalização e mundialização, assumindo os conceitos de apropriação da natureza por uma sociedade estabelecida em classes sociais. Ao final propõe uma discussão que considere uma nova razão para um novo conhecimento do fenômeno climático numa perspectiva social e de valorização dos recursos naturais.

Zavattini (2003) realizou estudo sobre "a abrangência temporal e espacial dos estudos do ritmo do clima no Brasil, tendo por base as teses e as dissertações produzidas nos programas paulistas de pósgraduaçao entre 1971 e 2000 e, também, o 'Inventário de Obras com Análsie Ritmica', elaborado por Zavattini (2001)"(p.65). o autor relata, ainda, que neste estudo foram "resgatadas algumas obras clássicas de Carlos Augusto de Figueiredo Monteiro, semeador do ritmo climático no país". (p.65). a abrangência temporal foi realizada entre o período, de 1941 a 2000, demonstando que, neste período, na abrangência espacial o Estado de São Paulo é o mais estudado pelo paradigma da análise rítmica, assim como a costa brasileira foi bastante estudada pelo paradigma da análise rítmica, assim como a costa brasileira foi bastante estudada. Em todo Brasil foram realizados inúmeros estudos com base em comparações rítmicas e estudos do ritmo do clima urbano, sendo que estes se encontram concentrados nas regiões Sudeste e Sul. "Entretanto, são também evidentes os enormes vazios rítmicos em nosso país, desde o Sul, passando pelo Sudeste e Centro-Oeste, até serem alcançadas as baixas latitudes do Norte e do Nordeste"(p.82).

Guerra (2004) faz um resgate dos livros que abordam a Geomorfologia, no Brasil e no mundo, sob os seus mais variados aspectos, com uma infinidade de características. Aborda conceitos sobre a Geomorfologia, bem como sua evolução ao longo do tempo e de que forma atualmente a Geomorfologia Aplicada vem ganhando força no mundo e no Brasil, como um ramo importante dentro da Geomorfologia, apesar de que muitos dos trabalhos que abordam essa área de conhecimento ainda estarem contidos em obras cujo título refere-se à Geologia. $\mathrm{O}$ autor discute, ainda, "os principais temas que a Geomorfologia tem abordado nos seus estudos, tendo sido de grande significado a compreensão dos processos geomorfológicos, como também no desenvolvimento desse ramo de conhecimento" (p.151), como: Geomorfologia Urbana, Geomorfogia das Áreas Rurais e Geomorfologia e Planejamento.

Tomasoni (2004) discute o caráter "transfronteiriço" do objeto da Geografia e a dificuldade que isso representa na identidade científica da disciplina. Discute, em seguida, a crise ambiental como produto das relações sociedade/natureza e o conceito de ambiente e sua aplicabilidade. Concluindo, o autor aborda o papel da Geografia Física no contexto do objeto geográfico.

\section{O UNIVERSO EMPÍRICO DE TRABALHO: A PRODUÇÃO DA GEOGRAFIA FÍSICA NO BRASIL}

O universo empírico dessa pesquisa constituiu-se por 22 periódicos (quadro 01)de geografia e 5 Periódicos e cadernos temáticos de geografia física (quadro 02). O levantamento foi realizado nas bibliotecas da UNESP de Rio Claro, na biblioteca da FFLCH-USP e, finalmente, na biblioteca da AGB-SP. Também realizamos o levantamento em 5 cadernos temáticos estão associados aos trabalhos desenvolvidos nos laboratórios do antigo Instituto de Geografia da USP e foram considerados na pesquisa dada a importância temática, metodológica e epistemológica que os mesmos representaram para a produção da geografia física no Brasil. 
Quadro 1 - Periódicos Considerados para o Levantamento de Artigos

\begin{tabular}{|c|c|c|}
\hline Periódicos & $\begin{array}{l}\text { Anos Iniciais e finais } \\
\text { Levantados na } \\
\text { biblioteca }\end{array}$ & $\begin{array}{l}\text { Intervalo de } \\
\text { publicação em } \\
\text { anos. }\end{array}$ \\
\hline Boletim Geográfico & $1943-1978$ & 35 \\
\hline Revista Brasileira de Geografia & $1939-1995$ & 56 \\
\hline Boletim Pautista de Geografia & $1949-2000$ & 51 \\
\hline $\begin{array}{l}\text { Revista da sociedade de Geografia do Rio de } \\
\text { Janeiro }\end{array}$ & $1928-1948$ & 20 \\
\hline Boletim Carioca de Geografia & $1949-1978$ & 29 \\
\hline Geografia (AGETEO) & $1976-2000$ & 24 \\
\hline Sociedade e Natureza & $1989-2000$ & 11 \\
\hline Geociências (UNESP) & $19 \pi 2-2000$ & 18 \\
\hline Boletim de Geografia Teorética & $1971-1995$ & 24 \\
\hline Boletim Goiano de Geografia & $1960-2000$ & 40 \\
\hline Boletim Paranaense de Geografia & $1960-1966$ & 06 \\
\hline Terra tivre (AGB) & $1983-2000$ & 17 \\
\hline Revista do Departamento de Geografia -USP & $1982-2000$ & 18 \\
\hline GEOUSP & $1992-2000$ & $O B$ \\
\hline Revista de Geografia (UNESP) & $1982-1996$ & 14 \\
\hline Geografia (USP) & $1944-1966$ & 22 \\
\hline Boletim UFPB & $1978-1988$ & 10 \\
\hline Boletim Departamento de Geografia-UNESP-PP & $1969-1974$ & 05 \\
\hline Boletim de Geografia-UEM & $1984-1996$ & 10 \\
\hline Boletim da Associaçăo dos Geógrafos Brasileiros & 1944 & 01 \\
\hline Caderno de Geografia (PUC-MG) & $1990-1998$ & 08 \\
\hline Boletim Mineiro de Geografia & $1951-1964$ & 13 \\
\hline Orientaçăo -USP & $1965-1993$ & 28 \\
\hline
\end{tabular}

Fonte: levantamento realizado por Antonio Carlos Vitte (2006-2007) na biblioteca de Geografia da Unesp-Rio Claro, FFLCH-USP e AGB-SP. 
Quadro 2 - Periódicos de Geografia Física (temáticos) levantados na biblioteca da UNESP de Rio Claro.

\begin{tabular}{|l|l|l|}
\hline Cadernos e Periódicos & $\begin{array}{l}\text { Anos Iniciais e finais da } \\
\text { ediçấo }\end{array}$ & $\begin{array}{l}\text { Intervalo da publicaçấo em } \\
\text { anos }\end{array}$ \\
\hline Geomorfologia & $1966-1980$ & 14 \\
\hline Paleoclimas & $1971-1979$ & 08 \\
\hline Climatologia & $1971-1977$ & 06 \\
\hline Noticia Geomorfológica & $1958-1981$ & 23 \\
\hline Biogeografia & $1969-1980$ & 29 \\
\hline
\end{tabular}

Fonte: levantamento realizado por Antonio Carlos Vitte (2006-2007) na biblioteca de Geografia da FFLCH-USP.

\section{Considerações sobre a Produção da Geografia Física no Brasil.}

Considerando que o espaço geográfico é uma representação cultural produzida pela hegemonia política de uma certa parcela da sociedade, que lhe atribuem significados e valores tanto à natureza quanto à sociedade. Para o desenvolvimento deste trabalho, foram pesquisados 22 periódicos nacionais especializados na temática geográfica, para um período de 78 anos (1928-2006). O quadro 03 representa a participação absoluta e relativa dos artigos de geografia física produzidos entre as décadas de 1920 e 1990.

Em termos absolutos, para um período de 78 anos (1928-2006) foram produzidos 6.189 artigos, sendo que destes, $2.298(37,1 \%)$ artigos tinham como temática a geografia física e 3.891(62,9\%) abordavam a geografia humana. A média geral de artigos para o período foi de 221,0 artigos/ano, sendo que a média de artigos de geografia física foi de 82,1 artigos/ano, enquanto que 138,9 foi a média de produção de artigos que não tratavam de geografia física.

Em relação o número de periódicos pesquisados, 26 no total, a média geral para os 78 anos foi de 238 artigos. Enquanto que a média de artigos de geografia física foi 88,3 artigos/periódico, a de geografia humana foi de 149,6 artigos/periódico.

Enquanto na década de 1920 os artigos de geografia física correspondiam à $0,1 \%$ do total de artigos, nas décadas de 1940, 1950, 1960 e 1970; este percentual alcançou 19,1\%, 19,8\%, 20,6\% e 15,7\% respectivamente. Sendo que os periódicos como o Boletim Geográfico (1943-1978), a Revista Brasileira de Geografia (1939-2005), o Boletim Paulista de Geografia (1945-2005) e o Boletim de Geografia Teorética (1971-1995) concentraram o maior volume de artigos de geografia física, assim como os de geografia humana. Somados estes quatro periódicos, os mesmos publicaram 1538 artigos de geografia física, representando 49,4\% dos artigos de geografia física produzidos no período de 1970 e $24,8 \%$ do total geral de artigos. Quanto à produção de geografia humana, foram publicados 3180 artigos, que percentualmente representa 51,3\% dos artigos produzidos no período de 1928 à 2006 e, em relação ao total de artigos de geografia humana, estes quatro periódicos concentraram $81,7 \%$ dos artigos.

Uma análise preliminar, o que fica evidente é que o aumento da produção da geografia física está relacionado tanto a processos que envolvem a especialização dos campos da geografia e sua renovação conceitual quanto à incorporação de novas tecnologias, que permitiram a institucionalização do saber geográfico a serviço do Estado.

As décadas em que percentualmente ocorreram as maiores freqüências de artigos de geografia física coincidem com os momentos de incorporação de novas fronteiras, como o Centro-Oeste e a Amazônia, e a conseqüente integração o território brasileiro, fatos que estão relacionados com a construção da iden-

Revista da ANPEGE. v. 4, 2008 
tidade nacional na qual a participação da geografia física ocorre por meio da qualificação dos atributos naturais do território brasileiro.

Quadro 3 - Participação Absoluta E Percentual Dos Artigos De Geografia Física Em Relação Aos De Geografia Humana Produzidos Entre As Décadas De 1920 E 1990, Em Periódicos Nacionais.

\begin{tabular}{|l|l|l|l|l|l|l|}
\hline Décadas & 1 & 6 & 2 & \% & 3 & \% \\
\hline 1920 & 3 & 0,1 & 6 & 0,1 & 9 & 0,1 \\
\hline 1930 & 12 & 0,5 & 26 & 0,7 & 38 & 0,6 \\
\hline 1940 & 439 & 19,1 & 1029 & 26,4 & 1468 & 23,7 \\
\hline 1950 & 455 & 19,8 & 637 & 16,4 & 1092 & 17,6 \\
\hline 1960 & 474 & 20,6 & 70 & 20,0 & 1219 & 19,7 \\
\hline 1970 & 362 & 15,7 & 454 & 11,7 & 816 & 13,2 \\
\hline 1980 & 257 & 12,9 & 485 & 12,5 & 782 & 12,6 \\
\hline 1990 & 256 & 11,1 & 495 & 12,7 & 743 & 12,0 \\
\hline TOTAL & 2.298 & 100 & 3891 & 100 & 6189 & 100 \\
\hline Média & 32,8 & 37,1 & 55,6 & 62,9 & 88,4 & 12,4 \\
\hline
\end{tabular}

Fonte: Levantamento realizado por Antonio C. Vitte (2006-2007) na biblioteca de Geografia da Unesp de Rio Claro. Legenda: 1 artigos de geografia física, 2 artigos de geografia humana, 3 total geral de artigos.

Uma vez que o momento político por qual o país passava era o da construção de um corpo político moderno e que tinha como missão modernizar à sociedade civil, a economia e a política. Para tanto, uma das estratégias possíveis era a conquista territorial. Dessa forma, dentro da diversidade fisiográfica em que está inserido o território brasileiro, a geografia física foi chamada para qualificá-lo, ao mesmo tempo em que reforçava a construção de uma imagem positivista da nação a partir das propriedades e exuberância da natureza no Brasil (VITTE, 1999).

Outra observação relevante é que enquanto na década de 40 as preocupações temáticas estavam voltadas para uma qualificação do espaço brasileiro, na tentativa de se construir uma visão simbólico-científica da natureza no Brasil, onde os grandes temas tratados pelos artigos diziam respeito a uma apresentação geral e primeiras impressões das viagens de campo para reconhecimento das regiões, na década de 50 os trabalhos passam a ser mais especializados e percebe-se já claramente a tendência de especialização nas pesquisas de geografia física (MENDONÇA, 1999).

É assim que a meteorologia e a climatologia passam a cada vez com maior força a delimitarem o seu objeto no sentido de definição de critérios metodológicos e técnicos, bem como definindo os principais eventos empíricos do clima (precipitação, temperatura, frentes, ritmos, tipos de tempo) que deveriam ser estudados no Brasil e que poderiam ser utilizados nos processos de correlação com o desenvolvimento econômico e social do Brasil (SANTANNA NETO, 2001). 
O mesmo acontecerá com a geologia, que já estará produzindo importantes e modernos mapas sobre o Brasil e já discutindo a tectônica no território brasileiro e sua influência na compartimentação do relevo brasileiro. Como são os clássicos trabalhos de Ruy Osório de Freitas sobre a tectônica no escudo brasileiro e o relevo policíclico (FREITAS, 1951), que tanto influenciaram a geomorfologia de Ab'Saber e Fernando Flávio Marques de Almeida.

A geomorfologia por sua vez, estará sofrendo pequenas mudanças metodológicas, proporcionadas pela realidade do espaço natural brasileiro, que direta ou indiretamente colocam questionamentos sobre o fazer geomorfologia, fato que está bem marcado na obra da primeira geração da USP, como João Dias da Silveira e Aziz Ab'Saber. E, é justamente Ab'Saber, que proporcionará a partir de seus trabalhos sobre o sítio urbano de São Paulo (AB'SABER, 2007) o início das mudanças metodológicas e futuramente epistemológicas na geomorfologia brasileira. Influenciado diretamente por Pierre Monbeig (AB'SABER, 2007a) procurará associar o método regional a compartimentação topográfica que por sua vez é condicionada pela litologia e estrutura, com os processos de aplainamento do relevo (ainda peneplanos em 1957), mas já denotando o descontentamento e a necessidade de um modelo paradigmático que melhor desse conta da realidade brasileira, que seria em breve a pediplanação. É assim, que em 1969 em sua livre docência (AB'SABER, 1969) realiza o grande salto qualitativo na geomorfologia brasileira com a pediplanação, mas incorporando o papel da tectônica e sua relação com os aplainamentos na compartimentação do território brasileiro.

Segundo Abreu (1982) as reflexões de Aziz representam o salto qualitativo não somente em termos de uso de técnicas na geomorfologia, como por exemplo, o uso de fotografias aéreas, mas também sob o ponto de vista epistemológico, à medida que o rompimento com o paradigma davisiano e a incorporação da pediplanação, não passou distante da crítica e da renovação conceitual e metodológica, da qual participaram também o professor João José Bigarella e a professora Maria Regina Mousinho Meis.

Estes constituem-se nos grandes difusores e ao mesmo tempo as principais estruturas do novo paradigma o climático, onde será fundamental a reflexão de Aziz Ab'Saber sobre os domínios morfoclimáticos e os redutos florestais do Brasil (AB'SABER, 1967).

Os anos 70 são marcados pela consolidação do paradigma climático desenvolvidos por Aziz Ab'Saber, Bigarella e Mousinho; ao mesmo tempo em que assistimos a uma intensa tecnificação do território e o processo de se conhecer detalhadamente as potencialdidades naturais do território nacional.

O que se observa atualmente, é que apesar desta nova quantificação que vivemos com as geotecnologias e o sensoriamento remoto, as problemáticas sociais e ambientais, atreladas à crise da Ciência Moderna inviabilizaram aquela maneira de se conceber metodológica e epistemologicamente a matematização do espaço geográfico, assim como a velha Teoria Geral dos Sistemas, que havia caminhado pari passu com a geografia quantitativa. A revolução einsteniana sobre o espaço e o tempo, a globalização da economia e o renascimento da geografia cultural colocaram para a discussão no meio acadêmico da geografia a necessidade de repensarmos a complexidade do real e neste, o sentido de espaço geográfico, sendo impossível agora, pensarmos a geografia e o espaço separado do tempo. Isto exige um novo diálogo entre a geografia humana e a geografia física sobre o objeto, e que objeto é este agora requalificado.

A crise ambiental não é outra senão uma crise existencial, portanto, que não pode ser resolvida por meio de milagres tecnológicos e soluções imediatistas e reducionistas (MENDONÇA, 2002). É uma crise que exige uma posição fenomenológica e ontológica sobre o ser e o fazer na geografia contemporânea, com graves implicações inclusive em nossa pós-graduação. 
Ao mesmo tempo em que a crise ambiental exige um repensar ontológico e um diálogo cada vez mais intenso entre a geografia física e a geografia humana, e da geografia com a metafísica, assistimos a uma enorme pulverização de periódicos de geografia, em sua grande maioria, vinculados aos programas de pós-graduação. Ao mesmo tempo, assistimos a um relativo esfacelamento dos departamentos de geografia, fragmentados em grupos de pesquisa e laboratórios, onde se vinculam pesquisadores experientes e pesquisadores iniciantes, alunos de graduação e pós-graduação, perdendo-se assim a visão do próprio departamento e do curso de geografia, enquanto instâncias formadoras e veiculadoras da ciência e de sua prática cidadã.

\section{CONSIDERAÇÕES FINAIS}

Uma análise sobre a produção da geografia física brasileira em vinte e dois periódicos de Geografia, permite-nos tecer as seguintes considerações:

a) A maior produção percentual de artigos de geografia física no Brasil, ocorreu nas décadas de 40, 50, 60 e 70, que historicamente estão associadas ao processo de desenvolvimento territorial, onde houve forte participação do Estado-Nação;

b) A geografia física no Brasil foi produzida essencialmente a partir de uma razão de Estado, cujo objetivo era a apropriação da natureza e com isto instrumentalizar o processo de acumulação capitalista;

c) A partir do final dos anos 40 e com maior intensidade nos anos 50, as várias disciplinas da geografia física, como a climatologia, a geomorfologia, a biogeografia, dentre outras, se especializam, cada qual com a definição epistemológica e metodológica de seu objeto, de suas técnicas e principalmente na construção das causalidades que influenciam o desenvolvimento de seus respectivos objetos regionais;

d) Das disciplinas da geografia física, a geomorfologia e a climatologia são aquelas que se especializam mais rapidamente e com muita intensidade, tanto assim, que a partir dos anos setenta, elas são capturadas pela geologia e pela meteorologia, respectivamente;

e) O surgimento da questão ambiental e a consideração sobre os limites do desenvolvimento capitalista no que diz respeito as relações homem-natureza; associadas as revoluções na física quântica, acabam por esfacelar os corolários positivistas que sustentavam as pesquisas em geografia e geografia física em particular. Havendo assim um repensar sobre o objeto de pesquisa, com muitas incertezas metodológicas. Fato que cada vez mais empurra a discussão sobre as bases filosóficas da geografia e da geografia física em particular e suas relações com as ciências humanas e cognitivas.

f) $\mathrm{O}$ que se observa atualmente é uma forte especialização nas disciplinas core da geografia física e isto, leva-nos a questionar, por exemplo, se haveria uma geomorfologia geográfica, ou se, ao contrário, dada a crise da Ciência Moderna e a aproximação da geomorfologia da geologia estrutural de do quaternário, a mesma já não se configuraria uma nova ciência, com uma lógica explicativa e argumentativa própria e um objeto próprio.

\section{REFERÊNCIAS BIBLIOGRÁFICAS}

ABREU, Adilson A de. Análise Geomorfológica: reflexão e aplicação. SP, Tese de Livre-Docência, Departamento de Geografia, FFLCH-USP, 1982.

ABREU, Maurício de Almeida. O estudo geográfico da cidade no Brasil: evolução e avaliação. In: CARLOS, Ana Fani A. (org.) Os Caminhos da reflexão sobre Cidade /Urbano. SP, Edusp, 1994. p.199-322.

ANDRADE, Manuel Correia de. O pensamento geográfico e a realidade brasileira. Boletim Paulista de Geografia, SP, n. 54, p.5-28, 1977. 
AB'SABER, Aziz N. Meditações em torno da notícia e da crítica na geomorfologia brasileira. Notícia Geomorfológica, ano 1, 1958, p.1-6. p.116-125.

Superfícies aplainadas do primeiro planalto do Paraná. Boletim Paraná de Geografia, n. 4/5, 1961,

. Revisão dos conhecimentos sobre o horizonte subsuperficial de cascalhos inhumanos no Brasil Oriental. Boletim Univ. Paraná, Geografia Física, n. 2, 1962, 32p.

. Domínios morfolclimáticos e províncias fitogeográficas do Brasil. Orientação, 3, 1967.

. Um conceito de geomorfologia a serviço das pesquisas sobre o quaternário. Geomorfologia, n.18, 1969.

. Províncias geológicas e domínios morfoclimáticos no Brasil. Geomorfologia, n. 20, 1970.

. O que é ser Geógrafo. RJ: Bertrand Brasil, 2007.

. Geomorfologia do sítio urbano de São Paulo. SP: Atelie Editorial, 2007a.

BECKER, Bertha; EGLER, Cláudio. BRASIL- Uma Nova Potência Regional na Economia-Mundo. RJ, Bertrand Brasil, 1993.

CAMARGO, José Carlos G. Evolução e tendências do pensamento geográfico no Brasil: a biogeografia. Rio Claro, Departamento de Geografia, Tese de Livre-Docência, 1998.

CIDADE, Lúcia C.F. Visões de mundo, visões de natureza e a formação de paradigmas geográficos. Terra Livre, SP, n. 17, p.99-118, 2001.

CONTI, José B. A climatologia e a defesa da natureza. Boletim Climatológico, Presidente Prudente, n. 2, p.5-9, 1996.

Depoimento sobre a produção em geografia física realizada na Universidade de São Paulo. Boletim de Geografia Teorética, Rio Claro, v.15, n.29-30, p.253-256.

GREGORY, K.J. A natureza da geografia física. RJ, Bertrand Brasil, 1992.

GUERRA, Antonio José T. Geomorfologia aplicada: algumas reflexões. In: SANTOS, Jemison Mattos dos. (org.) Reflexões e construções geográficas. Salvador, [s.n.], 2004,p.144-161.

MENDONÇA, Francisco de Assis. Geografia Física: ciência humana? SP: contexto, 1989, 72p.

. Geografia socioambiental. In: . KOZEL, Salete (org.) Elementos de Epistemologia da Geografia Contemporânea. Curitiba, UFPR, 2002, p.121-144.

MONTEIRO, Carlos Augusto de F. Geossistemas. SP, IG/USP, Série Biogeografia, 1978.

. A Geografia no Brasil (1934-1977): Avaliação e Tendências. Série Teses e Monografias, n.37, IG/USP, 1980.

. A questão ambiental no Brasil: 1960-1980. SP: Instituto de Geografia, USP, 1981, 133p.

SANT'ANNA NETO, João Lima. Por uma geografia do clima: antecedentes históricos, paradigmas copntemporâneos e uma nova razão para um novo conhecimento. Terra Livre, SP, n. 17, p.49-62, 2001.

SUERTEGARAY, Dirce e NUNES, João Osvaldo. A natureza da Geografia Física na Geografia. Terra Livre, SP, n. 17, p.11-24, 2001.

TOMASONI, Marco Antonio. Considerações sobre a abordagem da natureza na Geografia. In: SANTOS, Jemison Mattos (org) Reflexões e Construções Geográficas Contemporâneas. Salvador [Sn], 2004, p.11-35.

VIADANA, Adler Guilherme. Biogeografia: natureza, propósitos e tendências. In; VITTE, Antonio Carlos e 
GUERRA, Antonio José T. Reflexões sobre a Geografia Física no Brasil. RJ: Bertrand Brasil, 2004, p.111-128.

VITTE, Antonio Carlos. O texto no contexto. A tese de doutoramento de João Dias da Silveira “Estudo Geomorfológico dos Contrafortes Ocidentais da Mantiqueira". I Seminário Nacional de História do Pensamento Geográfico, Rio Claro: Anais..., Unesp, 1999.

ZAVATINI, João Afonso. Estudos do clima no Brasil. Campinas, Editora Alínea, 2005.

Recebido em abril de 2008 Aceito em agosto de 2008 